\title{
Rates of Drug Overdose Deaths Involving Heroin,* by Selected Age Groups — United States, 2006-2015
}

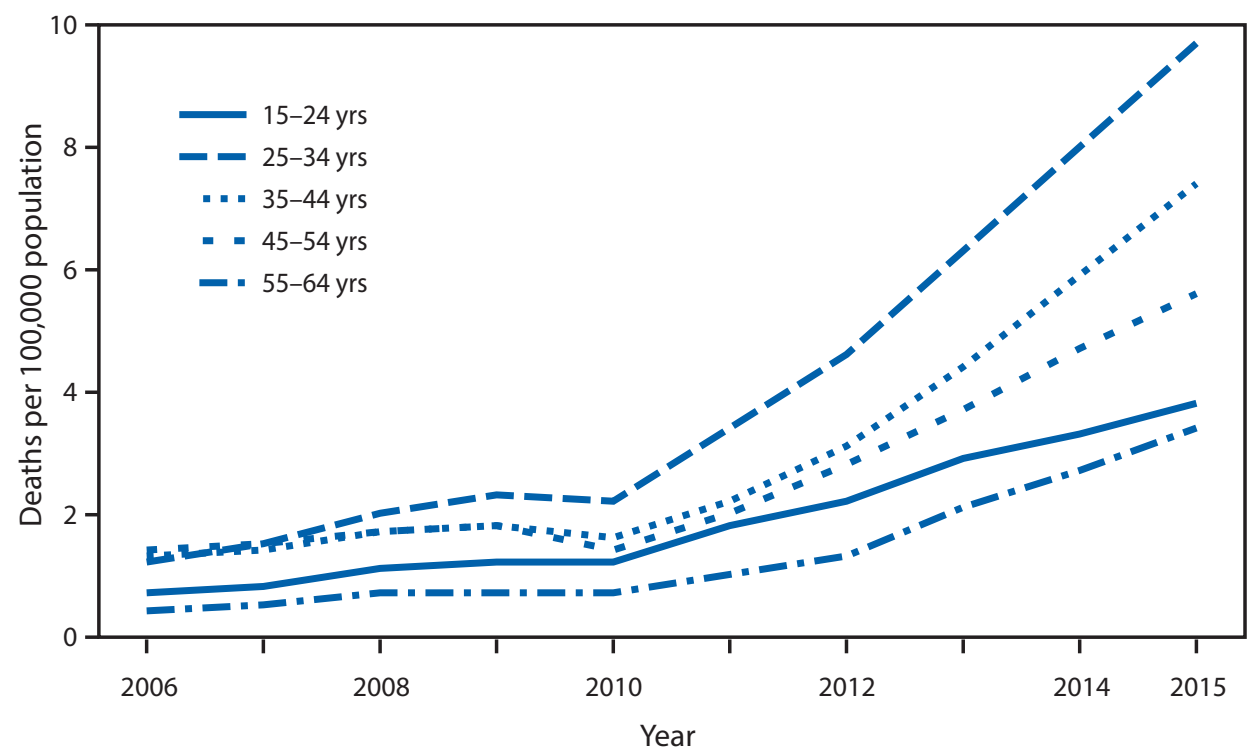

* Drug overdose deaths involving heroin are identified using the International Classification of Diseases, 10th Revision underlying cause of death codes $\mathrm{X} 40-\mathrm{X} 44, \mathrm{X} 60-\mathrm{X} 64, \mathrm{X} 85$, and $\mathrm{Y} 10-\mathrm{Y} 14$, with a multiple cause of death code of T40.1. During 2006, there were 2,088 drug overdose deaths involving heroin (age-adjusted rate of 0.7 per 100,000 population); during 2015, there were 12,989 deaths (age-adjusted rate of 4.1).

The rate of drug overdose deaths involving heroin increased slightly during 2006-2010 but more than tripled during 2010-2015 for all age groups shown. During 2010-2015, the rates increased from 1.2 to 3.8 per 100,000 for persons aged 15-24 years, from 2.2 to 9.7 for persons aged 25-34 years, from 1.6 to 7.4 for persons aged 35-44 years, from 1.4 to 5.6 for persons aged $45-54$ years, and from 0.7 to 3.4 for persons aged 55-64 years. In 2015, the rate of drug overdose deaths involving heroin was highest for persons aged 25-34.

Source: National Vital Statistics System mortality data. http://www.cdc.gov/nchs/deaths.htm.

Reported by: Holly Hedegaard, MD, hdh6@cdc.gov, 301-458-4460; Margaret Warner, PhD; Arialdi M. Miniño, MPH.

For more information on this topic, CDC recommends the following link: https://www.cdc.gov/drugoverdose/states/index.html. 